\title{
MACHADO REDIVIVO OU AI SE ELE SOUBESSE O QUE FIZERAM COM CAPITU
}

Marcos Zibordi*

\begin{abstract}
lgum tipo de leitor deve pensar que ao crítico é mais fácil criticar no sentido negativo, de apontar defeitos, do que criticar no sentido positivo, 1 elogioso. Engano. É um duplo desafio criticar no sentido negativo, pois impõe a necessidade de apontar pelo menos racionalmente as causas dos defeitos, como também de não parecer emocionado, revanchista, e queimar a obra sem explicá-la. Percebendo bem, surge ainda uma terceira dificuldade, esta de ordem interna, que o crítico deve tentar superar: é ter que escrever sobre o que, em última análise, ele não gostou, mesmo que este julgamento tenha lá sua parcela de distanciamento e critério.

É com esses problemas que vamos lidar e é o que nos faz pensar o curtinho livro Enquanto isso em Dom Casmurro (1993), do blumenauense José Endoença Martins, criação da série ficcional contemporânea sob a perspectiva da obra machadiana, que analisaremos com os olhos de leitores da virada do século-milênio. Assim, para ler Enquanto isso..., o exercício analítico e o esforço textual impostos resultam naquelas três premissas enumeradas acima: análise racional e/ou teórica, explicação de um certo julgamento de gosto, além da autosupervisão constante para a necessária atitude otimista frente à empreitada.
\end{abstract}

* Universidade Federal do Paraná. 
Vamos a ela. Sob a recorrente justificativa da "linguagem", o blumenauense Endoença procura engendrar um diálogo com Capitu, uma das máximas personagens da criação ficcional brasileira, a mãe de todas, por assim dizer. Como isso se dá? Ela sai de Dom Casmurro e terrifica na capital catarinense, sob a figura fantasmagórica de uma negra vestida de country-girl, de pink, chapéu e faixinha na testa. Dotada do poder de materializar seus pensamentos, logo faz surgir o apartamento e a ninfetinha empregada loira. Começa quente sua aventura na nova vida.

E por que Capitu veio parar nessa espécie de Oktoberfest dos horrores? Para requerer de Machado de Assis, então professor de literatura na universidade local, que reescrevesse sua história, dando-lhe mais dignidade, posição feminina. A premissa, o argumento, até que é interessante, se pensarmos no achatamento da personalidade feminina de Capitu operada pelo doentio marido-algoz Bentinho em Dom Casmurro. Por outro lado, só pra que fique registrado, a possibilidade mais forte de leitura do romance aponta o contrário, ou seja, a garota dos olhos de ressaca é uma mulher forte, decidida social e sexualmente, muito à frente das cocotinhas futriqueiras do seu tempo. Não é porque o ponto de vista desabonador do romance é sempre do narrador-acusador que não é possível inferir a leitura de uma Capitu muito mais forte que o edipiano Bentinho.

De qualquer maneira, a premissa é aceitável. No entanto, a tentativa intertextual moderninha de Endoença não se sustenta, levando a pensar que nem mesmo ele tenha tido dimensão da possibilidade literária que provocou. A forma como a nova Capitu se coloca no mundo é de uma grosseria constrangedora. Qualquer mulher que esperasse do livro alguma espécie de redenção de classe, detestaria o estado puta-lésbico-louca ao qual o nosso estreante romancista a reduziu. Um trecho que resume o espírito da obra: Machado, após um ataque epilético durante a inesperada visita de Capitu, tem uma ereção, no que emenda o autor:

A nossa pós-moderna personagem aproveitou a ereção de Machado de Assis e se valeu do pau duro e quente do seu criador para foder e gozar inúmeras vezes.

Existem outros desdobramentos.

O diálogo entre Dom Casmurro e Enquanto isso..., da mesma forma, não acontece plenamente e afunda antes da outra margem do precipício, dando a 
impressão de que o autor pescou de orelhada alguma eventual discussão sobre procedimentos estéticos na pós-modernidade. É como a imagem clássica do desenho animado: vem correndo o patinho para transpor o abismo com um pulo, mas não consegue fazer a ponte, e cai precipício abaixo.

O exemplo mais claro dessa não-interação entre os romances: as esporádicas "visitas" de Capitu ao original Dom Casmurro, e as mais esporádicas ainda de Bentinho a Enquanto isso... - elas têm muito pouco ou nada a ver com a história que Endoença pretende estar contando. Nesse trânsito em transe, a intenção da destemida Capitu era ter sua vida e obra reescritas, mas o romance muito pouco trabalha nesse sentido, tanto que o livro acaba e Machado não modificou uma linha sequer da personagem original. Ou seja, enquanto o assunto pressupõe-se e propõe-se um, os personagens se reentramam muito pouco para quase nada de significativo, como a exploração da curiosidade sexual banal.

Então Bentinho vem conferir a performance da nova dama e também faz seus requerimentos. Claro, nessas ocasiões ela aproveita para lhe dizer algumas verdades, mas tudo ainda naquele tom de empregada doméstica, de discussão de casais embriagados de rabo-de-galo em bailão com música country, estilo de vida que o autor tanto condena.

Decorrente disso, a crítica à brega moda de Florianópolis, regida pelo padrão Sula Miranda de ser, merece comentário. Endoença não gostou da invasão agro-contry na cidade praieira, com seu guarda-roupa de bota, fivela, chapéu e respectivo aparato sonoro na festa antes étnica e talvez mais digna que os rodeios. Será? Em que sentido a Oktoberfest é mais digna que os rodeios?

Amostras desse "nativo melhor que a moda alienígena" são fartamente lidas quando Endoença se põe a criticar a babaquice dos costumes e as invasões turísticas. O que vemos é aquele limar mole de botequero sindicalista, incansavelmente apontando os desvios, os absurdos, o mau gosto do consumo - um ressentido, enfim. É um Enéas das letras e esse apontar superficial e constante, excessivo, mala mesmo, faz imaginar que ele proporia concertos eruditos em pleno calçadão de Florianópolis como antídoto ao mal da moda, e que pretenderia ainda que eles fossem mais fortes que o movimento do mundo e contivessem a onda dos mercados. A crítica rasteira só beneficia quem menos pretende, quer dizer, o próprio mercado, já que se torna um discurso apaziguador.

Por falar em mercado, não custa assinalar a narrativa rápida, com alguns recursos de versificação e estrofes, cenas quentes, cocaína, lesbianismo entre exótica negra e angelical branca, tudo ao gosto dos melhores clipes da semana ou da Madonna. Isso também é mercantilização, e menos ética que a venda dos produtos de Sula Miranda, que são declaradamente comerciais e não se 
pretendem literatura. Comparando, é como se, na música, de repente algum desses sertanejos de calça apertada passasse a criticar o estilo do qual faz parte, usando para isso os mesmos pressupostos do que pretende rejeitar. Seria um milionário criticando um José rico, abanando na cara do outro os cordões de ouro ou latão bem polido.

Finalizando, uma última opinião, que esperamos não ser confundida com capricho crítico ou teórico. Endoença chama de "linguagem" o canal que permite sua tentativa de intertextualidade mal-sucedida. Em todo momento repete linguagem, linguagem, mas está sempre querendo nomear o que na verdade se chama metalinguagem, quer dizer, o exercício intertextual.

Linguagem, como sabemos, é tudo, da língua à linguagem da língua e do beijo, da cena ao quadro, é o que universaliza o particular. O exercício intertextual não deixa de ser um exercício de linguagem, mas neste caso se caracteriza sobretudo como metalinguagem, no sentido de transferências de referências de um romance ao outro, de contraposição criação-recriação, de personagens e situações que se combinam e recombinam, de reflexão enfim sobre a própria construção literária. A distinção é pertinente porque o que se confunde na nomeação teórica, em última análise desnecessária, explica o fato da intertextualidade não ter funcionado. Talvez por isso os recortes de revistas que abrem os capítulos são intertextualmente mais significativos do que a tentativa principal de transfusão entre os dois romances. As reproduções da entrevista e da matéria com Sula Miranda são mais interessantes, sutis, artísticas, no que concerne ao procedimento estético intratextual e à crítica da moda local, que o autor faz por apontamento excessivo e pouco revelo crítico.

Começamos com uma chatice necessária, que é explicar Dom Casmurro, ou pelo menos uma questão central: mais uma vez é preciso dizer que não se trata de um romance sobre traição. É o livro que mergulha no abismo de uma sofisticada vida repressiva, demonstrando do começo ao fim como ela pôde prejudicar o filho da dona Glória nas suas relações, principalmente afetivas, e de como esse fardo foi decisivo para seu desencontro total. É antes de tudo psicológica a história contada pelo protagonista retrospectivo, um doentio frustrado, relembrando de sua acanhada juventude, casta e canhestra, julgando desde lá ou antes sua deliciosa, decidida e atrevida vizinha. Claro que, nessa história, a complexidade psicológica de Bentinho, do Dr. Bento Santiago e do narrador Dom Casmurro é construída e sustentada principalmente em relação à dúvida que virou certeza - a traição de Capitu. 
Daí uma das chaves do romance, que não se deve perder de vista: o tempo todo é ele - amante, namorado, marido, viúvo - quem olha para ela, e não o contrário. Na verdade, do ponto de vista da narrativa, não há dúvida para Dom Casmurro no final do relato: "Escobar e Capitu se juntaram, me traíram, e a terra lhes seja leve!"

Então, qual é a dúvida? A dúvida veio depois, da crítica, que colocou em xeque a certeza do narrador - mas era justamente isso que Machado de Assis queria! Ao que parece, o desmascaramento do narrador foi resultado, em termos críticos, da interpretação cada vez mais ampla que alcançamos das obras literárias. Tratou-se e trata-se de tornar nós, leitores, e não só de literatura, e não só de livros nem de textos escritos, menos ingênuos diante de quem profere um discurso, sua posição autorizada para tal, e as implicações decorrentes. Desconfiar do narrador é desconfiar da História.

Entretanto, uma vez feita a constatação em relação a Dom Casmurro, que se presta a ser nosso melhor exemplo literário nesse sentido, ela se reverteu na pergunta persistente se Capitu traiu ou não. Queremos dizer o seguinte: em termos de ciência histórica, desmascara-se necessariamente Dom Casmurro. Do ponto de vista da estrutura interna da narrativa, desmascarar o narrador é destruir o texto, explicar a piada, justamente porque ela se sustenta na dúvida - é um texto certeiramente duvidoso. Mas não parou por aí. Professores de altos títulos se põem a recriar a obra machadiana insistindo que a mais sensual personagem da literatura brasileira, a primeira, a cigana tesuda e libertadora de todos nós, mulheres e homens, era uma simples interesseira e traiçoeira.

Desfazer a dúvida, extrair o ponto de vista, é acabar com o mote e com a mira. E portanto esclarecer se o narrador tinha ou não razão é simplesmente desmontar o romance, não de uma maneira produtiva criativamente, mas inútil do ponto de vista crítico-criativo, e praticamente irrelevante do ponto de vista histórico, porque nós já sabemos que faz tempo que o narrador, o Galvão Bueno da vez, torce pelo time da casa. Apesar de todo o resto do mundo monumental machadiano embutido em Dom Casmurro, ele parece não ser suficiente para que a maldita pergunta deixe de ser feita: Capitu traiu Bentinho? Imaginamos que todos os professores de cursinho e apostila, maledicentes mauricinhos do xaveco literário, ouvirão a pergunta na entrada do inferno e, uma vez lá dentro, seu eterno tormento será ouvir sempre como resposta a qualquer pergunta a pergunta que eles perpetuaram em vida: Capitu traiu Bentinho?

Numa inocente volta pela livraria, por exemplo, topa-se com qualquer uma dessas reedições do romance e, na contracapa, impressa em vermelho, está a pergunta. Mas isso não é só problema das edições clássicas isentas de imposto. 
É também o que norteia a contemporânea produção romanesca e pós-moderna que retoma temas, personagens e textos de Machado de Assis, mas principalmente sua obra máxima. Uma olhada nos títulos basta para constatar: os autores querendo esclarecer o mistério da traição.

Contudo, começamos frisando o que nos parece ser a principal questão, a retomada incoerente da pergunta que, assim, é a principal constatação crítica em análise.

Depois de uma bad trip com José Endoença Martins, nos é apresentado Capitu: memórias póstumas (1998), do nosso segundo professor de literatura, crítico liberto e profeta prafrentex, Domício Proença Filho.

E o que ele vai fazer? Adivinha: mais empenhado que Endoença, ele retoma ponto por ponto o texto original (depois o chamaremos de originário) e dá uma reposta sobre o não-adultério na voz de Capitu, emancipada, mas anja, com a bagagem secular do feminismo e a fortuna crítica machadiana municiando sua defesa em estilo de tribunal, como se no século passado tivesse deposto o Dr. Bento Santiago e agora, morosidades da justiça, chegara a vez da esposa dar sua versão. Ela, é natural, tem ajuda de outras figurinhas conhecidas do salão machadiano, além do que sabe Domício sobre o assunto.

O século de crítica já esclareceu, e Domício sabe disso, que em Dom Casmurro a namorada de Bentinho e a esposa do Dr. Bento Santiago são a mesma pessoa, ou seja, uma personagem plana como se diz, que tem um projeto claro e definido desde o começo da trama, e o mantém. A Capitu da releitura também. Ela se defende do começo ao fim sem, contudo, perder o dom de iludir, reafirmando o oblíquo e dissimulado sem considerar que quem a via assim a via de viés, olhos no chão e mãos tremendo. Domício reescreve Capitu oblíqua com os olhos de Bentinho. Qual a novidade, o avanço, o passo crítico então? Nenhum, e em alguns aspectos, há mesmo o retrocesso.

Como por exemplo na afirmação machista por trás de toda essa insistência na traição de Capitu. $\mathrm{O}$ conceito de traição, também contemporâneo à defesa escrita desse clone pós-moderno da personagem, não pressupõe uma regra moral, mas ética, e Domício também sabe disso. Hoje, trair é quase que exclusivamente trair a si mesmo. O romance, discutindo se traiu ou não, continua falando de uma adúltera em hipótese, o que já é o bastante para ser adúltera de fato. São confusões, equívocas e estéreis, mantidas até hoje. Em uma frase, para pensar na cama: o que está em jogo em Dom Casmurro não é a explicação dos fatos, mas a estética resultante de um caso de lógica perfeita arquitetada e materializada pelo narrador. Machado de Assis consegue materializar o que não se admitia. 
E Domício continua explicando. Agora sua Capitu entra de sola, direto na canela de Bentinho sobre ser ela mais mulher que ele homem: o maridão, diga-se tudo, não cumpriu com os deveres de varão nem na lua de mel e pelo jeito nem depois. Era homossexual. E somos de novo obrigados a reargumentar que a interpretação mais coerente da personagem machadiana sugere: o problema do menino, desde criança, era sua sexualidade problemática, não e mal-resolvida. Um Bentinho homossexual, vulgarmente fora do armário, teria que ser muito macho para tal atitude em Dom Casmurro e sua época; mas fica quase real no romance de Domício.

Essa Capitu, que é anja, junto com a Capitu diabólica e lésbica de Endoença, são os personagens pós-modernos recriados até agora, em graus diferentes de estereótipos e preconceitos.

Vai daí que Domício demonstra não ter gostado do excesso de referências em Machado. Taticamente falando, em Capitu: memórias póstumas percebemos, entre outros palpitantes, o que chamamos de a mão do técnico, do "professor" teimoso e preciosista que está dizendo não ter se afeiçoado às citações e paralelos com os clássicos em Dom Casmurro. E assim passamos de uma avaliação da obra prioritariamente para uma crítica da crítica que Domício faz.

E o que ele faz é explicar, explicar Dom Casmurro através de Capitu: memórias póstumas, dando, portanto, utilidade didática ao livro, que quase não pode ser lido sem o conhecimento prévio do antecessor.

Parece haver uma contradição na afirmação que acabamos de fazer, que junta didatismo e leitura especializada. Mas estamos justamente dizendo que se trata de um didatismo para leitores com o mínimo de informação sobre o assunto, mesmo que distorcida, ou para espectadores que querem se especializar tanto no texto machadiano quanto em sua fortuna crítica. Seria demais considerá-lo paradidático?

Aqui, afirmamos utilidade literalmente. Não é o caso de perguntar para que serve o romance de Domício, em que panorama da estética atual se coloca ou com quais se relaciona. Antes da pergunta o livro chega impresso num sentido, a relação inescapável com Dom Casmurro. É para ele que aponta. Sem a dependência parasitária, praticamente não existe. É um conceito totalmente diferente daquele conhecido e belamente explicado, entre outros, pelo poeta curitibano Paulo Leminski, o da literatura como inutensílio, algo que não precisa dessa razão causal aparente para existir, cuja elucidação é, no limite, intangível e dispensável. É como querer racionalizar a genialidade do gol de bicicleta.

Estamos tentando apontar o primeiro problema, a primeira diferença séria que estas obras impõem à teoria: o exercício útil da escrita literária, como inequívoco esforço de elucidação crítica e estética da outra, da que a originou. 
Isso é bem diferente da relação que Machado de Assis estabelece com outras obras em Dom Casmurro, por exemplo, ou que outros livros estabeleceram na história da literatura. Certo, literatura se alimenta de literatura, mas seria imaginável um caso-limite dela se alimentando só dela?

Até então a ponte entre as obras permitia falar em autonomia, ou graus de autonomia. A produção pós-moderna que estamos analisando trata de dialogar e recriar diretamente, claramente touro e toureiro. Nela há um enfrentamento direto da obra originária, caso explícito em Domício. Houve um tempo em que se citava. Agora se fala de fora e de dentro do outro.

Dessa constatação é que então ajustamos para esta discussão o conceito de obra original. Ela seria melhor designada como originária, que suscitou uma outra obra a partir dela. Original carrega o sentido de um parto, ou de uma obra que possa dar à luz uma outra. Dom Casmurro não pariu nenhum desses livros fisicamente, no máximo os provocou. Já existe inclusive um personagem famoso que representa a relação parasitária dessas obras com as criações machadianas, ora infiltrando preconceitos ardilosos no discurso, ora adubando interesseiros sonhos, batendo e soprando, entre superlativos e mesquinhezas, jogando nos bastidores e ganhando no tapetão: seu nome é José Dias.

É como uma imagem que discute com quem está na frente do espelho que o trabalho de reescrita caracteriza o crítico como legislador. Seria um retrocesso crítico? Estariam hoje os professores de literatura para os médicos que criticavam obras nos jornais de antanho, apontando o bom e o ruim? É evidente e inevitável o tom legislativo e processual da produção pós-moderna que estamos analisando. E este é o segundo apontamento para a teoria: além do problema da utilidade, o da posição advocatícia da recriação.

Raciocinemos: explorar potenciais da obra originária seria realmente reescrever a história, só e mecanicamente invertendo ou alterando o ponto de vista? É assim que estão respondendo a questão até agora. Depois de uma Capitu puta, e outra armada e astuta, não deve demorar a surgir o romance com o ponto de vista de José Dias, do Pádua, da Tia Justina, da Sancha e, principalmente, do Escobar. E aquela possibilidade dele ter tesão ou interesse pela dona Glória?...

Um romance-recriação didaticamente utilitário e funcionalmente condenatório é estranho do ponto de vista pedagógico, quase paradoxal, porque dele emerge um professor-profeta, que quer instruir legislando, que quer formar informando, que quer de alguma forma atualizar o que, como obra-prima, é sempre atual. Nesse sentido, o desejo de perpetuação não evidencia nem o originário (Dom Casmurro) nem o resultante (Capitu: memórias póstumas), mas o sujeito: 
aquele autor, que antigamente era confundido com o narrador da obra, agora está de volta. A distinção teórica mostrou que o narrador é uma criação do autor, portanto não é aquele mesmo sujeito físico que senta para escrever. Mas nesses livros parasitários é quase impossível dissociar o homem da obra.

Assim é também na situação mais extrema da clonagem. O que se descobre é que a duplicação dos seres pode ser bem sucedida e, apesar de impor uma relação perpétua entre eles, pode até dar certo, e vir a ser bela, harmônica. Mas, o que não se poderá evitar, no caso da clonagem e das recriações, é o fato delas nunca mais se explicarem sem a presença de quem as fez em laboratório - e não dos que tiveram suas células originárias usadas na experiência. Pai, nesse caso, não é o dono do primeiro gen, mas quem os manipulou. As criaturinhas se apagam na busca da diferenciação identitária, apavorados com sua imagem tal e qual pelas ruas, mas é sempre um médico audacioso o criador do elo entre o originário e o originado, pretensão que não tinham as co-dependências literárias promovidas pelos autores de outras obras até então. Digamos que antes no máximo se ousava uma inseminação artificial. Hoje, o clone é colocado no útero sem que a dona ou o pai biológico saibam.

Chegamos ao terceiro e último desdobramento teórico resultante da interpretação dos textos, e principalmente de Capitu: memórias póstumas. Ao explicitar a co-dependência literária, levando-a a um ponto em que as obras não mais sobrevivem sem o texto original, estreita-se a tal ponto a relação do autor com a recriação e desta com a obra primeira, que emerge sempre sua figura egocêntrica de ousado autor pós-moderno. Ele anda pomposo com um filhotinho debaixo de cada asa, como D. Glória sabia fazer muito bem. Falamos agora da Capitu de Machado, de Domício, de Endoença, de Sabino e de Beltrano.

No fim das contas, estamos diante de um romance metaficcional que responde ao que não havia sido perguntado e faz da resposta uma defesa jurídica utilmente preconceituosa, esbanjando teoria, prática e aplicação. E também estamos diante de um egocentrismo autoral emergente. Serve para começar a pensar o quanto essa constatação vale para o contemporâneo mais amplo no Brasil, que dialoga também com a história, com outros livros e personagens. E também para pensar o quanto elas podem servir a um didatismo que, em última instância, é autoritário porque simplesmente inverte os pólos de força da questão, é maniqueísta; e, enfim, para refletir o quanto elas podem sobreviver por si mesmas e quais são as figuras que estão fazendo, cada uma no forno de barro do fundo do quintal, sua Capituzinha moderna. 
Para Amor de Capitu, de Fernando Sabino, adotamos uma perspectiva mais ampla do que talvez seja crítica, refletindo que visada sociológica vai na medida em que uma característica verificável na sociedade pode ser apontada dentro da obra, fazendo parte da sua economia interna.

Primeiro aspecto: Amor de Capitu é um calhamaço estranhamente editado. Tem lá uma apresentação do autor; a recriação vem em seguida, ocupando umas duzentas páginas; depois temos outro capítulo, "E bem, e o resto?", em que Sabino encerra suas considerações da introdução, texto que deveria estar junto com a apresentação, pois a completa; a seguir vem um quarto e último capítulo, um apêndice, não se sabe bem a razão dele, mas são umas cinqüenta páginas do Machado cronista, quer dizer, seleção de alguns capítulos de Dom Casmurro em que o narrador é comentarista dos fatos do seu tempo.

Os motivos de Fernando Sabino estão expostos na introdução e no que segue à recriação propriamente dita. Deviam estar juntos, mas antes de falar deles, vamos aproximar Amor de Capitu de Capitu: memórias póstumas, de Domício Proença Filho, anteriormente analisado.

Registramos o problema da utilidade didática da obra, que se presta a uma explicação ou explicitação do livro originário; notamos a posição autoritária delas enquanto procedimento pedagógico e em relação à própria interpretação restritiva do texto-base; e, enfim, dissemos que delas emerge sempre a silhueta do criador pós-moderno. No livro de Sabino ocorre a mesma coisa.

Ele também se presta a uma incursão explicativa de Dom Casmurro, fato claro na adoção estratégica do narrador em terceira pessoa, para fins de desnudamento, ou no teor das questões do suplemento de apoio pedagógico de Amor de Capitu, que é parte integrante da obra e não pode ser vendido separadamente. Mas Sabino responde diferente de Domício o livro originário. Apesar de reescrevê-lo, não o faz obsessivamente e ponto por ponto; praticamente não cita Dom Casmurro de forma literal, embora faça uma paráfrase muito próxima. Seria por isso menor o grau de positivismo? Não.

Sua prerrogativa é, como explica na introdução, pensar até que ponto "a dúvida teria sido premeditada pelo autor, através de um narrador evasivo". A resposta, se alguém ainda não disse: a dúvida foi premeditada por Machado de Assis até o máximo grau através do seu autor não tão evasivo assim.

Mas vamos à recriação. $\mathrm{O}$ autor de Zélia, uma Paixão, adota o narrador objetivo em terceira pessoa, em substituição à primeira pessoa impressionista de Machado de Assis, para “eliminar o narrador Dom Casmurro como intermediário entre os fatos por ele vividos e o público leitor”. Mesmo que fosse possível 
eliminar o narrador, isso não mudaria praticamente nada no que diz respeito aos fatos arrolados, para falar em tom de tribunal.

A mudança do narrador, pura e simples, é de uma ingenuidade muito grande, se não for má fé. Sabino dá uma limpada no original, elimina as digressões, as suspensões narrativas e as ricas impressões do narrador. Ideal ascético.

A narrativa se transforma num realismo positivista sem nenhuma chance para o simbolismo. É uma operação de caráter prático, que troca o Galvão Bueno por uma atendente telefonista sem nenhum tesão.

Descontada a emoção que saiu do ar, não avulta nenhuma novidade interpretativa desse novo narrador, até porque o jogo é o mesmo, e Fernando Sabino acredita "óbvia" a traição de Capitu, logo na introdução.

Consideramos suficiente o que foi dito anteriormente sobre o adultério ou não da personagem, em relação ao livro de Domício. Contudo, Sabino arrola mais duas provas no tira-teima "É bem, e o resto?", que nos obriga amargamente a respondê-lo.

Ele pergunta "como Capitu podia saber que o cavaleiro com quem trocava olhares suspeitos ia se casar com uma amiga sua, se declarou ao namorado que nem sequer o conhecia?"

Fomos ao capítulo 16, como ele indica, já desconfiado. A passagem do cavaleiro acontece 57 capítulos depois, no 73, intitulado, ironicamente, "O ContraRegra". Nele, Bentinho fica apavorado com a possibilidade da traição e só acalma dali três capítulos, no chamado "A Explicação". Mas Sabino está equivocado, ele que diz ter relido Dom Casmurro tantas vezes e lista, como é de costume, uma estante de fortuna crítica machadiana que diz ter escarafunchado. É só ler com atenção: Capitu não diz em nenhum momento que a noiva do cavaleiro era sua amiga. A frase é em relação ao rapaz, e diz o seguinte, na voz do narrador: "confessou-me que não conhecia o rapaz, senão como os outros que ali passavam às tardes". Ou seja, levando em consideração a verossimilhança interna do romance, é no sentido de "senão como os outros" que Capitu sabia do seu casamento "com uma moça da rua dos Barbonos".

Já a segunda "prova" que Sabino arrola não é falsa, mas frágil. Ele afirma que "fosse ela [Capitu] inocente, como sustentara, era pouco provável que elogiasse tanto, conforme contou ao filho, um marido que a repudiasse injustamente".

Não, olhando para o romance, seria mais provável que ela elogiasse o marido, levando-se em conta a postura digna, altiva e resignada com que a personagem vive sua história. 
Isso sobre didatismo, inversão mecânica e sem efeito do narrador, e os contra-argumentos da acusação de adultério. Pensamos que na capa de Amor de Capitu, o nome de Fernando Sabino maior que o título do livro é suficiente para ilustrar a tal figura egocêntrica desses recriadores.

Amor de Capitu é a recriação mais rasa e menos criativa de todas até agora. Quer provar, e não prova, que o narrador em terceira pessoa pode elucidar o mistério que não existe. E é até estranho um esforço tamanho para quem a traição de Capitu é inegável. Seria melhor ter escrito um arrazoado com suas razões.

Não acontece com a operação de Sabino, mas o narrador em terceira pessoa pode se tornar um enganador muito mais sutil que o de primeira pessoa, justamente por criar uma ilusória noção de distanciamento, fato fartamente discutido pela teoria literária e até mesmo por algumas teorias da comunicação em relação ao narrador pseudo-distanciado do texto jornalístico.

O libelo positivista de Fernando Sabino merece exatamente uma frase explicativa de Machado de Assis, escrita numa crônica de 1859, quando o escritor tinha então vinte anos e comentava assim a atividade dos que chamava de parasitas literários: "meia dúzia de folhas de papel dobradas, encadernadas, e numeradas é um livro; todos têm direito a esta operação simples, e o parasita por conseguinte".

No fim da leitura do romance de Sabino ficamos tentando achar alguma outra obra de literatura brasileira de recriação, algum livro que já tivesse dialogado anteriormente com outras obras, personagens da ficção ou situações da história. E não foi preciso ir longe, topando de novo com Paulo Leminski e seu Catatau.

A premissa do poeta é genial: colocar Descartes na Recife colonial. Descartes, por pouco, não veio para o Brasil junto com Maurício de Nassau. Dizem que Leminski se perguntou um dia, em voz alta, durante uma aula de cursinho, o que poderia acontecer se ele tivesse vindo mesmo. Estava armada a ratoeira literária, sobre a qual o poeta trabalhou oito anos, até o livro vir a público em 1975. Temos o pai do cartesianismo fumando aquela erva de negros e espiando constantemente por uma lente as partes do gigantismo da floresta. $\mathrm{E}$ dá-lhe bicho-preguiça, trepadas, gosmas, numa prosa poética de turbilhão, realizada no mais alto grau.

De quebra, estabelece uma outra freqüência temporal no romance, já que se trata, entre outras coisas, de questionar os parâmetros do tempo artificial do relógio. E muito mais. Como disse o Décio Pignatari, está tudo lá.

Indiquemos o polaco louco das araucárias para os nossos novos romancistas. Catatau neles! 
Comentaremos, agora, o mais interessante dos quatro romances pósmodernos que dialogam com a obra machadiana. Memorial do Fim (1991), de Haroldo Maranhão, não cai em praticamente nenhuma cilada que seus contemporâneos congênitos caem. Ao invés de Dom Casmurro, Maranhão vai cotejar Memorial de Aires, sem no entanto abandonar uma visada mais ampla para outros personagens e situações da obra de Machado de Assis. Como bem observou Marilene Weinhardt, o romance se constrói com fusões:

Fusão do indivíduo Machado de Assis e dos diversos narradores machadianos, fusão do escritor e de várias de suas personagens, fusão do discurso machadiano e do discurso de Haroldo Maranhão.

Essa amplitude responde de imediato àquela falta de criatividade que reclamávamos nas recriações. O texto agora funde e sintetiza, resultando num clima machadiano, e o que se lê é uma incursão às penumbras, incertezas, cortinas translúcidas sugerindo casmurros ou moribundos do outro lado, toda a atmosfera e contexto do pai de Capitu. E, melhor, Maranhão inventa uma outra história para contar os últimos dias de Machado de Assis.

Memorial de Aires é o livro em primeiro plano para Maranhão. O derradeiro escrito machadiano - de um sentimento de morte terrivelmente conciliador, balizado, condescendente, meditativo - em Memorial do Fim vira uma espécie de fantasmagoria contida em que passam personagens históricos, personagens machadianos transmutados, mas ainda característicos e identificáveis, gente que quer chegar, tudo morrendo assim inexoravelmente como a volta da cortina branca depois que o vento a balança e a faz repousar nos batentes da janela - o moribundo se vê indo com ela, mas ainda não foi, vai daqui a pouquinho, ou já foi e só restou o gemido e o cheiro de mofo.

Sobre a estrutura do romance, o seu encadeamento lógico e construtivo, toda essa população de Memorial do Fim é controlada e auferida com precisão pelo autor. No texto, entretanto, a busca de uma expressividade genuinamente machadiana escorrega em alguns momentos - um risco inevitável em tal projeto. A estratégia narrativa entrecortada, os suspenses, os recursos que vão de cartas a anotações do Conselheiro Ayres (ou não) são suficientes para reconstituir uma certa noção de história, que é o aspecto lúgubre do passado na obra, ou seja, o caráter melancólico, sombrio, triste e, em última instância, funesto de 
Machado de Assis. É o que falta aos outros romancistas: uma noção de história. Maranhão recupera o pessimismo machadiano, que diz respeito à maneira como ele nos encarava historicamente. Os outros autores, positivistas ainda um século depois, ao fazerem suas recriações reafirmam a construção histórica linear, cartesiana, do começo-meio-fim, tão caro aos românticos, noção da qual Machado não compartilhava. Cremos mesmo que ele não concordaria nem com certa noção distorcida de miscigenação, depois travestida em democracia racial. No Brasil, a cordialidade, no caso machadiano desde José Dias, é antes o resultado humilhante e cordato da risível (des)união nacional, ou melhor, o "homem cordial" é sobretudo um patético alienado e seu patrão não é exatamente um amigo sincero na visão de Machado de Assis, "por trás carcomida". Bentinho, que confessa ter chorado pela morte de José Dias, nem sequer sabia o quanto era opressor, para falar agora como Paulo Freire. Aliás, seus momentos de maior masculinidade (excitante), ocorrem em relação ao agregado (se bem que incentivados por Capitu). Uns e outros no Brasil, os da casa-grande e os da senzala, são tristes desterrados, na maioria dos casos sem consciência do fato. Para Machado de Assis nossa história é um impasse e não é preciso mais que Pedro e Paulo em Esaú e Jacó para aferir com que pessimismo ele via a transição Império-República e, no mais, todo o resto.

Memorial do Fim, cronologicamente anterior aos quatro romances, permanece sendo o mais interessante deles. E agora, voltando a pensar na distinção entre obra original e originária, verificamos que a invenção machadiana, sendo originária do romance de Maranhão, tem nele resgatada a trajetória estética e o posicionamento histórico. Vale aqui lembrar Linda Hutcheon, em Uma Teoria da Paródia. A autora diz que paródia não é mera imitação nostálgica, sendo antes "uma confrontação estilística, uma recodificação moderna que estabelece a diferença no coração da semelhança". O sentido de "diferença no coração da semelhança", como faz Maranhão com Machado, está explicado assim, páginas adiante, pela teórica:

A paródia é, pois, na sua irônica "transcontextualização" e inversão, repetição com diferença. Está implícita uma distanciação crítica entre o texto em fundo a ser parodiado e a nova obra que incorpora, distância geralmente assinalada pela ironia. Mas esta ironia tanto pode ser apenas bem humorada, como pode ser depreciativa; tanto pode ser criticamente construtiva, como pode 
ser destrutiva. O prazer da ironia não provém do humor em particular, mas do grau de empenhamento do leitor no "vai-vém" intertextual.

Quanto ao que apontamos nos outros romances, ao aproximar aquelas conclusões de Memorial..., constatamos que aqui elas não se repetem. Primeiro que o trabalho de Maranhão não pode ser acusado de didatismo utilitário. Pelo contrário, não pretende explicar a obra, antes a confunde e refunde, requerendo o leitor mais especializado dos quatro romances, um leitor cuja capacidade de relacionar correspondências seja maior que o daqueles capazes de, no máximo, olhar a coisa pelo contrário - o que é diferente de olhar pelo avesso. Não se trata de um romance para quem leu um ou dois livros de Machado de Assis, o que, felizmente, não deixa ele se tornar uma leitura facilitadora (e nem hermética). Outra que Maranhão não está nem um pouco interessado em revelar ou desvelar ou valorizar Capitu. Não é condenatório, acusatório ou defensor. Simplesmente não julga - está mais interessado em recriação que em avaliação.

Eis então o livro que é um título autônomo, um cabeça-ombro-perna-e-pé por si mesmo. Não o identificamos como a recriação de fulano ou beltrano. Maranhão é até modesto demais quando admite e justifica sua pretensão em recriar Machado de Assis; vai logo se desculpando, ou admitindo antes que o façam por ele.

Seu livro provocou aquele resultado estético mencionado na apresentação, além de uma óbvia felicidade crítica. E principalmente por ser capaz de mostrar de que forma é possível recriar num grau mais alto de elaboração, mostrando como fazer para balizar as influências de cá e de lá, no jogo certeiro e bem entrosado entre originário e recriação.

\section{RESUMO}

Exame do conjunto dos romances que estabelece o jogo intertextual com Machado de Assis, concluindo que os escritores buscaram diálogo com o cânone sem estatura para o confronto, exceção feita a Haroldo Maranhão.

Palavras-chave: ficção histórica, metaficção, cânone. 


\section{ABSTRACT}

Examining of novels which plays an intertextual game with Machado de Assis, it concludes that the writers (excepting Harold Maranhão) tried unsuccessfully a dialogue with the canon.

Key-words: historical fiction, metafiction, canon.

\section{REFERENCIAS}

HUTCHEON, Linda. Uma teoria da paródia. Ensinamento das formas de arte do século XX. Lisboa: Edições 70, 1989.

LEMINSKI, Paulo. Catatau. Porto Alegre: Sulina, 1989.

MACHADO DE ASSIS, Joaquim Maria. Esaú e Jacó. 10. ed. São Paulo: Ática, 2000. . Memorial de Aires. 12. ed. São Paulo: Ática, 2000.

. Contos consagrados. 4. ed. Rio de Janeiro: Ediouro, 1997.

. Memórias póstumas de Brás Cubas. 7. ed. Rio de Janeiro: Ediouro, 1997.

. Dom Casmurro. 2. ed. São Paulo: Cered, 1991.

. Quincas Borba. 5. ed. São Paulo: Ática, 1973.

. Contos. Obras completas. 8. ed. São Paulo: Cultrix, 1961.

. Crônicas, Crítica, Poesia, Teatro. Obras Completas. 3. ed. São Paulo: Cultrix, 1961.

MARANHÃO, Haroldo. Memorial do fim: a morte de Machado de Assis. São Paulo: Marco Zero, 1991.

MARTINS, José Endoença. Enquanto isso em Dom Casmurro. Florianópolis: Paralelo 27, 1993.

PROENÇA FILHO, Domício. Capitu: memórias póstumas. Rio de Janeiro: Artium, 1998.

SABINO, Fernando. Amor de Capitu. São Paulo: Ática: 2001. 
SCHWARZ, Roberto. Criando o romance brasileiro. Argumento, p. 19-47, fev. 1974. Que horas são? São Paulo: Cia. das Letras, 1987.

.Um mestre na periferia do capitalismo. São Paulo: Cia. das Letras, 1990.

. Seqüencias brasileiras. São Paulo: Cia. das Letras, 1999.

. Duas meninas. São Paulo: Cia. das Letras, 1997. 